\title{
Tomato Automation Cultivation System: Automatize Watering and Fertilizer Based On Sensory Information
}

\author{
Kok Seng Eu, Choon Hwa Ang, Yoon Ket Lee, Tee Tiong Tay, Yeh Huann Goh, Choe Yung Teoh
}

Faculty of Engineering and Technology, Tunku Abdul Rahman University College, Kampus Utama, Jalan Genting Kelang, 53300 Kuala Lumpur

\begin{abstract}
This research is to build a tomato watering and fertilizing machine for household-based agriculture. The objective is to reduce the work of planting the tomato tree, keeping the tomato tree stays healthily, and increase the interest of the people on the innovative agriculture in the household. This project aims to increase the efficiency of planting tomato, by reducing the tomato growth period and promoting the innovative way of planting. The planting of tomato tree in the household environment has a high chance of suffering diseases such as black spot disease, mould leaf disease, and yellow leaf disease, due to reasons of poorly controlling of temperature, watering, and humanity. The outcome of this automated cultivation machine can prevent the tomato trees away from the above-mentioned diseases. In conclusion, the automated cultivation machine provides an eco-farming environment that closes to the natural environment and the tomato tree not only grow healthy but also speed up the growing process in the machine. Moreover, the size of the machine is suited to household and promotes the interest of the people in household-based agriculture.
\end{abstract}

\section{Introduction}

The food and water are highly consumed nowadays because the population in the world are getting increasing, and the crops and clean water are just merely enough supply to the people [1].

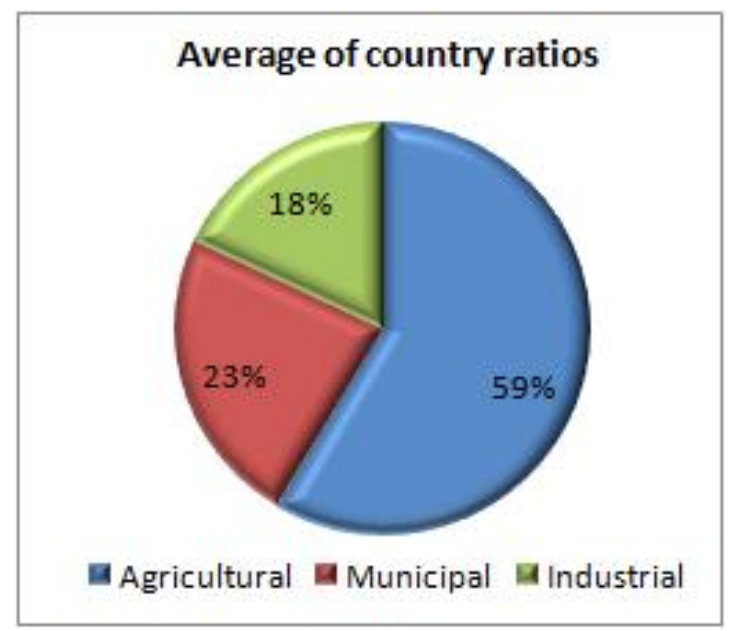

Fig. 1. Area of water used chart [1].

As shown in Fig. 1, agriculture uses more water than other sectors. Therefore, this issue can be solved by controlling the watering system to be more effective in the agriculture sector $[2,3]$. In Malaysia, the import of the fruit and vegetable are larger than export; although there are many of land in Malaysia was used in the agriculture. Therefore, the contribution from the field of agriculture to Gross domestic product (GDP) is low. It was around $30 \%$ of total GDP in 1970, but after 30 years later, the ratio of GDP that contributed from the agriculture sector dropped to $8.4 \%$ only [4] [5]. There are many reasons for the dropping of productivity in agriculture, one of the main reasons is related to the tough work and low incomes of the farmers.

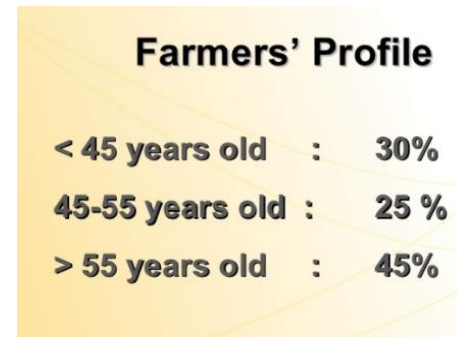

Fig. 2. Farmer Profile in 2009 [6].

Fig. 2 shows the age population of the farmers, it is around $70 \%$ of farmers are more than 45 years old and hence, thus indicating that the young generations are not working in agriculture. This is because agriculture in Malaysia is lack of technical support and the working environments are uncomfortable if compare to the office jobs [6-7]. Agriculture 4.0 is new to innovate the concept of traditional agriculture, bring the current technology into the agriculture and agriculture innovation to attract the young people, hence, changing the career perspective in agriculture.

The challenge of this project is to use microcontroller technology to control the watering and

* Corresponding author: euks@tarc.edu.my 
fertilizing, which based on the sensing feedback, such as temperature, and humidity, to make the machine stable and getting the tasty and juicy fruit in the machine. The problem of this project is that the poor automatic controlling of watering and fertilizing causes disease of the plant, such as black spot disease (Fig. 3), mould leaf disease (Fig. 4) and yellow leaves (Fig. 5). Each disease is caused by different reasons: humidity level too and the environment not ventilated causes the black spot disease; For the mould leaf disease is due to the soil moisture level too high at night; and lastly, the lacking of iron in the soil causes the yellow leave disease. Each disease can be prevented, the proper controlling of automatic controlling of watering and fertilizing, and reproducing of friendly environment parameters.

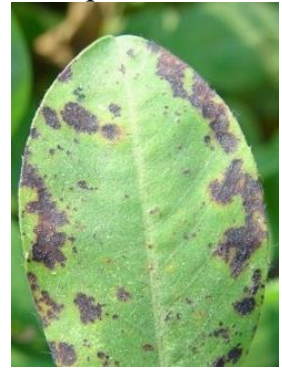

Fig. 3. Black Spot Disease

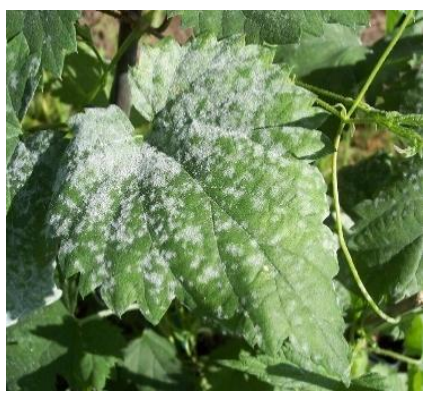

Fig. 4. Mould Leaf Disease

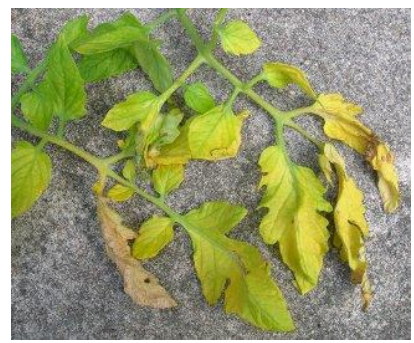

Fig. 5. Yellow Leaf Disease

The objective of this research is to study the tomato growth behaviour by using sensors, to use the water efficiently for tomato tree and to control the resource supply to the plant by using the microcontroller. Another objective is to design a homestyle tomato automation system, to grow the tomato tree in the household environment. This provides a convenient way for people, who live in the city with a busy lifestyle, enables them to eat fresh fruits which planted by themselves.

\section{Related Work}

The Photosynthesis is the key to growing fruit and vegetable. During the photosynthesis, not only water and fertilizer are absorbed to grow the plant and bear fruit, but also sunlight is needed to help the plant growth. Therefore, in this research, the sunlight can be replaced with ultraviolet (UV) light-emitting diode (LED).

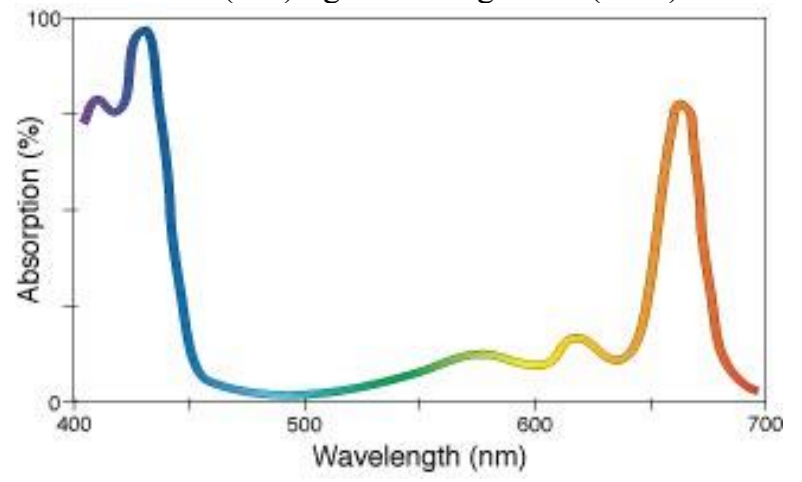

Fig. 6. The Light Wavelength Absorption for plant [8]

Fig. 6 shows the absorption of a different wavelength of UV LED, and the highest is $450 \mathrm{~nm}$ and $650 \mathrm{~nm}$. Both wavelengths must be used because each type has a different function. If only used either one, the plant will not stay alive [8] [9].

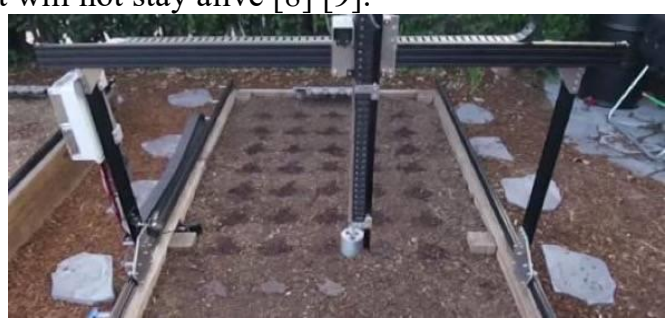

Fig. 7. The FarmBot Genesis [10]

FarmBot genesis [10], as shown in Fig. 7, which can plant vegetable and fruit automatically. This machine can perform the watering and fertilizer process based on the information stored on the internet. The structure of this machine is similar to a $3 \mathrm{D}$ printer and it used a large area to plant the vegetable. However, this machine is located in an outdoor open space, which means that the machine has no ability to control the growing environment such as temperature, and humidity [10] [11].

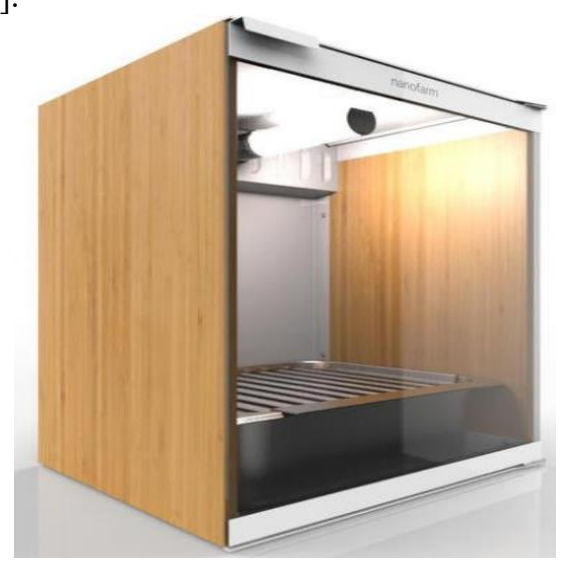

Fig. 8. NanoFarm model [12]. 
The NanoFarm, as shown in Fig. 8, is to plant vegetable in a small and close machine. The seed is placed in the machine and the LED light replaces the sunlight. After that, the growing period of the vegetable is studied. When the vegetable is ready to be eaten, the indicating light is turned on, to remind users to harvest it. The machine is portable and suitable for the traveller with the car to eat fresh vegetable anytime. [12] [13].

TABLE I. COMPARISON TABLE OF RELATE WORK

\begin{tabular}{|l|l|l|}
\hline \multicolumn{1}{|c|}{ Type } & \multicolumn{1}{c|}{ Advantage } & \multicolumn{1}{c|}{ Disadvantage } \\
\hline $\begin{array}{l}\text { FarmBot } \\
\text { genesis }\end{array}$ & Water Saving, Intelligent & $\begin{array}{l}\text { Space Consuming, } \\
\text { Environment Effect }\end{array}$ \\
\hline NanoFarm & $\begin{array}{l}\text { Portable, Environment } \\
\text { Not Affected }\end{array}$ & $\begin{array}{l}\text { Not for fruit, No Data } \\
\text { Collection }\end{array}$ \\
\hline
\end{tabular}

Table I shows the comparison of both relate works. FarmBot genesis is water saving and intelligent, but the disadvantage is the space consuming and environment affected. On the other hand, NanoFarm is a portable and self-controlled environment. However, it lacks data collection and people do not know the machine situation. Each machine has its own advantages; it would be great if able to combine both advantages, will be more useful to the agriculture to plant more crop and saving the space used.

\section{Experiment Platform}

In this research, the experiment focus is on the tomato plant. We used Arduino Uno as the microcontroller. Besides, we used an LCD to display the information and all the data that collected from the humidity sensor and realtime clock module. Furthermore, the data are stored in micro SD card through the MicroSD module. After that, the stored data is used to determine the actions controlling the mini water pump, heater lamp and UV LED lamp.

The design of the automated cultivation machine has a rectangle structure, as shown in Fig. 9. This is because the tomato plant will be grown vertically.

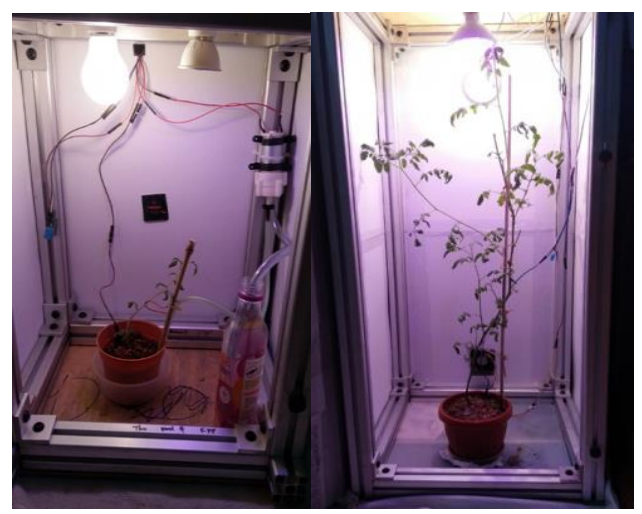

Fig. 9. Automated cultivation machine.

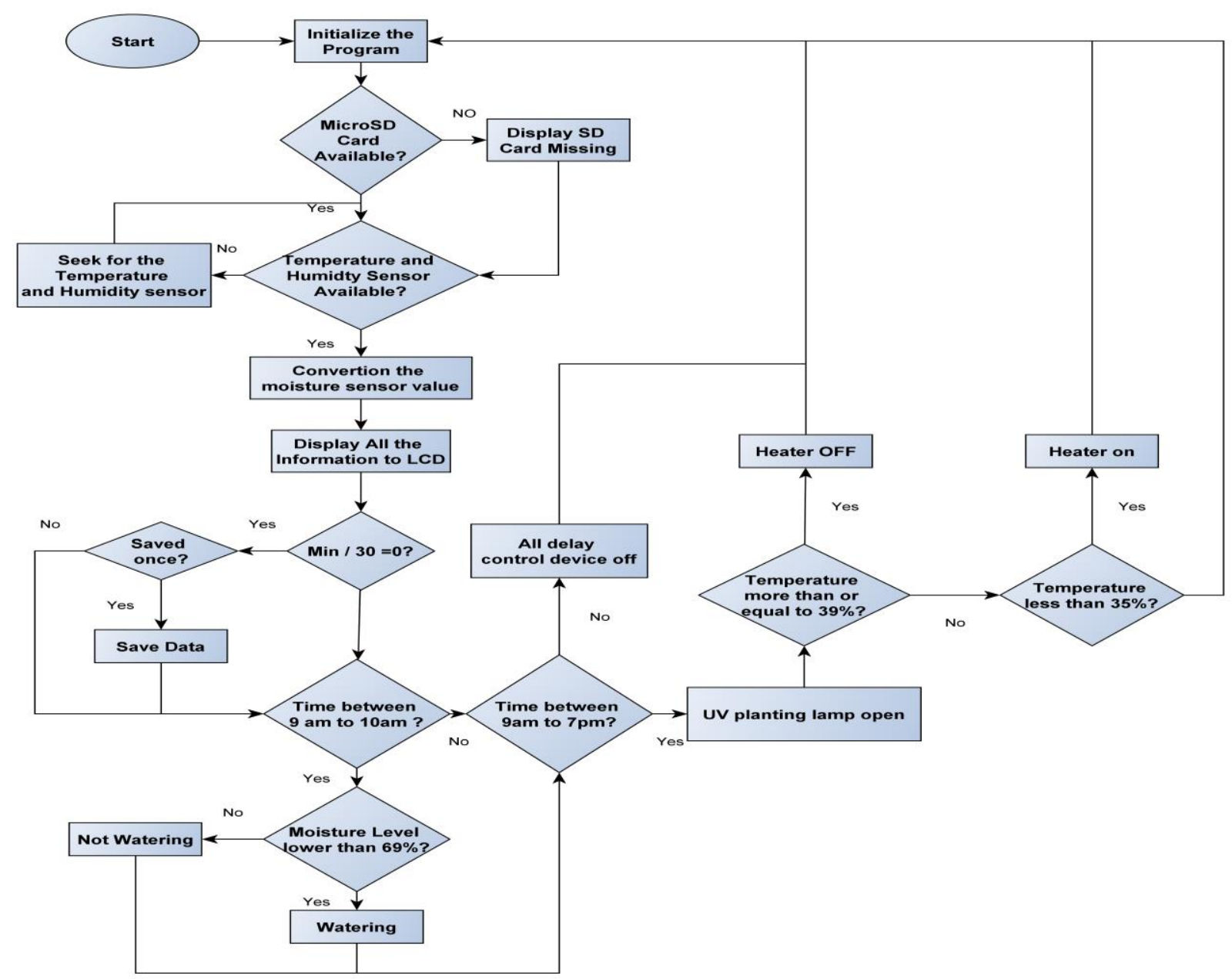

Fig. 10. Flow Chart of the Software Program 
The machine is programmed by $\mathrm{C}$ program, the flow of the program is from the initialization the sensors to the operating of the actuator. In the beginning, the machine checks from the analogue readings of the humidity sensor and then displaying the sensing values on the LCD screen. After that, the program makes a decision based on the sensors readings, to control the heater lamp, planting lamp and the watering motor. For the data collection will be recorded every 30 minutes and store to microSD memory card. The machine waters when the time is from 9 am to 10 am and the moisture level is below $69 \%$. If the moisture level is above $69 \%$, the pump will not be turned on for watering. For the planting, the lamp will be switched on from 9 am to 7 pm and the heater lamp will be switched off when the temperature is more than $39 \mathrm{oC}$; but it will be switched on again when the temperature is lower than $350 \mathrm{o}$. All the pump and lamp will be switched off after $7 \mathrm{pm}$, as shown in Fig. 10.

\section{Result and Discussion}

The research process involves two stages: the first stage is to measure natural environment parameters that suitable to grow a tomato tree. These environment parameters are temperature and humidity. The measurements are taken without raining (to simplify the study) but the manual watering is performed every morning at $9 \mathrm{am}$. All the measurement of environmental parameters is recorded down for reproducing purpose in the later stage. The second stage is to use the automated cultivation machine, locating in a household environment, and then controlling the mini water pump, heater lamp and UV LED lamp, in order to reproduce environment parameters that measured previously in the first stage.

\section{A. Stage one- the measurement of natural environment parameters}

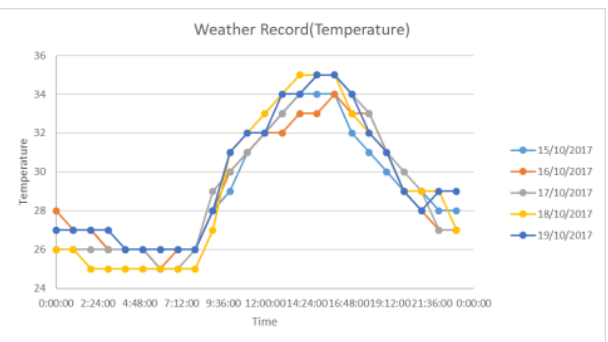

Fig. 11. Weather Data(Temperature)

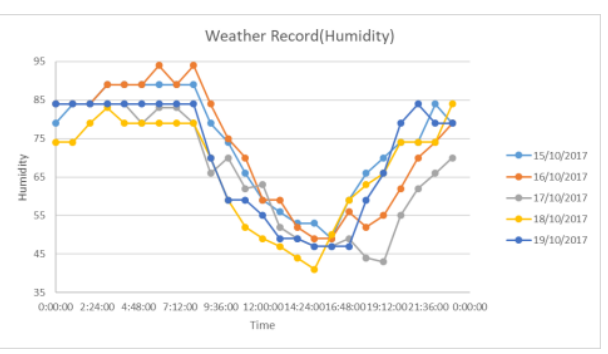

Fig. 12. Weather Data(Humidity)
Fig. 11 and Fig. 12 shows the measurement of natural environment parameters (outdoor). The data were collected for five days and the temperature increases from 9 am until around $2 \mathrm{pm}$. After that, the temperature drops until $7 \mathrm{pm}$. Therefore, the peak of the temperature is between 9 am to $7 \mathrm{pm}$ and the rest of time that temperature is around $27 \mathrm{oC}$. However, the data for humidity in reverse of the temperature level. The humidity level gets lower from 9 am and increases after $2 \mathrm{pm}$. The period between 9 am to $7 \mathrm{pm}$, humidity is lowest. In the contrast, humidity is higher in between 0 am to $7 \mathrm{am}$.

\section{B. Stage two-reproducing the environment parameters} with the automated cultivation machine

In this stage, the automated cultivation machine, locating in a household environment and then controlling the mini water pump, heater lamp and UV LED lamp, in order to reproduce environment parameters that measured previously in the first stage.

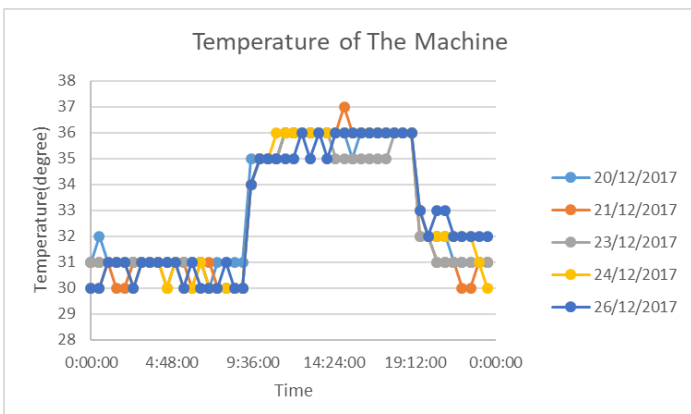

Fig. 13. Machine Environment (Temperature)

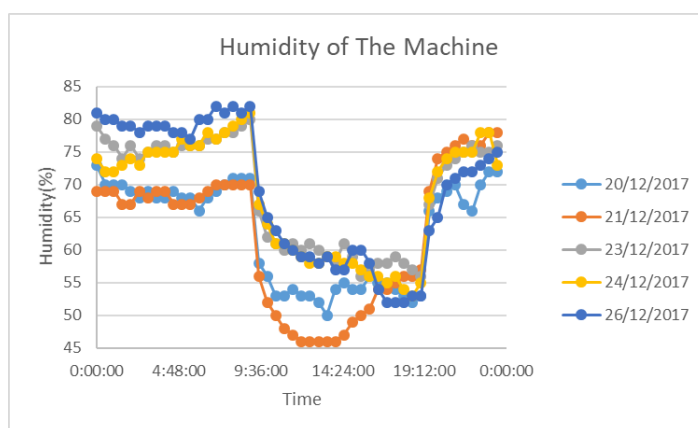

Fig. 14. Machine Environment (Humidity)

Fig. 13 and Fig. 14 shows the measurement readings of machine environment are identical to the measurement of natural environment parameters in the former stage. This indicated the reproduce of environment parameters are successful.

The success of reproducing of environment parameters, enables the tomato seed are able to grow in the machine with the healthy condition. The period of the seed growth is 5 days and constant. This can overcome the tomato seed in the outdoor environment with the unstable weather because in an outdoor environment would have raining weather and the period of the seed growth would be longer than usual. For the

\footnotetext{
* Corresponding author: euks@tarc.edu.my
} 
leaf stage of tomato in the machine are able to grow with the healthy condition. In the beginning, the height of the tomato plant is in $35 \mathrm{~cm}$ height and after a week the tomato plant was growth until $45 \mathrm{~cm}$. The leaves of the tomato plant in the machine were in good and green condition. In the observation, two of the new branch was growth in the machine and to let the tomato plant had more flower and fruit.

During the experiment, some of the diseases of the tomato plant happened and all of it had been solved, when we able to reproduce the optimistic environment parameters. The diseases were included black spot disease, mould leaf disease and yellow leaf disease. The black spot disease happen is because the humidity level and moisture level too high and the environment are not ventilated. The solution is to add a fan in the machine to keep the environment ventilated. The mould leaf disease happen is because of the high humidity level at the night. This is because the tomato can digest the nutrition and rest at night. After that, the yellow leaf disease happens when the irons of the soil are not enough and the water flow in the soil is too much, the iron of the soil will be a loss. The solution to prevent mould lead disease and yellow leaf disease is to control the watering system only at morning when the heater lamp is open and watering the tomato plant is necessary.

\section{Conclusion}

In this research, the temperature level and the humidity level for the tomato plant had been studied and collected, subsequently, those data were used to program the machine by controlling it using a microcontroller. As the result, the machine was able to grow the tomato from the seed stage to the leaf stage without any disease.

\section{References}

1. AlanEmery, "Human Population Increase - How Are We Doing?," 2015. [Online]. Available: http://www.kivu.com/human-population-increasehow-are-we-doing/. [Accessed 1 August 2017].

2. F. a. A. O. o. t. U. Union, "Water Uses," 2016. [Online]. Available: http://www.fao.org/nr/water/aquastat/water_use/inde x.stm. [Accessed 1 August 2017].

3. W. Staff, "FARMS WASTE MUCH OF WORLD'S WATER," $2006 . \quad$ [Online]. Available: https://www.wired.com/2006/03/farms-waste-muchof-worlds-water/. [Accessed 1 August 2017].

4. V. Yong, "Recapitulation: Sustainable and Inclusive Transformation of Malaysia Agriculture Sector," 2017. [Online]. Available: https://www.linkedin.com/pulse/recapitulationsustainable-inclusive-transformation-malaysia-yong. [Accessed 23 December 2017].

5. T. ECONOMICS, "Malaysia GDP From Agriculture," 2017. [Online]. Available: https:/tradingeconomics.com/malaysia/gdp-fromagriculture. [Accessed 23 Decemer 2017].
6. Ranzccdadavao, "Overview Of Agriculture Sector In Malaysia," 2009. [Online]. Available: https://www.slideshare.net/ranzcdadavao/overviewof-agriculture-sector-in-malaysia-presentation. [Accessed 24 December 2017].

7. M. M. Alam, "Agricultural Economics and Rural Development," SOCIOECONOMIC PROFILE OF FARMER IN MALAYSIA:, vol. VII, no. 2, pp. 249-265, 2010.

8. M. Schirber, "The Full Palette of Photosynthesis," 2013. [Online]. Available: https://www.giss.nasa.gov/research/features/201311 _kiang/. [Accessed 3 January 2017].

9. YingchaoXu, "Optik - International Journal for Light and Electron Optics," The research on LED supplementary lighting system for plants, vol. 127, no. 18, pp. 7163-7201, 2016.

10. FarmBot.Inc, "FarmBot Genesis," 2011. [Online]. Available: https://farmbot.io. [Accessed 1 August 2017].

11. A.Hayward, "The FarmBot Genesis Brings Precision Agriculture to Your Own Backyard," 2016. [Online]. Available: http://www.smithsonianmag.com/innovation/farmbo t-genesis-brings-precision-agriculture-your-ownbackyard-180959603/?no-ist. [Accessed 30 July 2017].

12. Replantable, "Nanofarm," 2015. [Online]. Available: https://replantable.com/products/nanofarm. [Accessed 3 August 2017].

13. R.Stella, "PLANT, WAIT, EAT: THE NANOFARM LETS ANYONE GROW FRESH PRODUCE INDOORS," 2016. [Online]. Available: https://www.digitaltrends.com/home/replantablelaunches-nanofarm-home-planter/. [Accessed 3 August 2017]. 